OPEN ACCESS

Edited by:

Ramadhansyah Putra Jaya, Universiti Malaysia Pahang, Malaysia

Reviewed by:

Mohd Zul Hanif Mahmud

University Technology Malaysia,

Malaysia

Zul Fahmi Mohamed Jaafar, Universiti Sains Malaysia Engineering Campus, Malaysia

*Correspondence:

Zhi Suo

suozhi@bucea.edu.cn

Specialty section:

This article was submitted to Structural Materials, a section of the journal

Frontiers in Materials

Received: 08 January 2021

Accepted: 22 February 2021

Published: 15 March 2021

Citation:

Suo Z, Chen H, Yan Q, Tan Y, Li X

and Zhang $A$ (2021) Laboratory

Performance Evaluation on

the Recovering of Aged Bitumen With

Vegetable Oil Rejuvenator.

Front. Mater. 8:650809.

doi: 10.3389/fmats.2021.650809

\section{Laboratory Performance Evaluation on the Recovering of Aged Bitumen With Vegetable Oil Rejuvenator}

\author{
Zhi Suo ${ }^{1 *}$, Huan Chen ${ }^{1}$, Qiang Yan ${ }^{1}$, Yitian Tan ${ }^{1}$, Xinghai Li ${ }^{2}$ and Ao Zhang ${ }^{2}$ \\ ${ }^{1}$ Beijing Urban Transportation Infrastructure Engineering Technology Research Center, Beijing University of Civil Engineering \\ and Architecture, Beijing, China, ${ }^{2}$ Beijing Road Engineering Quality Supervision Station, Beijing Key Laboratory of Road \\ Materials and Testing Technology, Beijing, China
}

Generally, the conventional rejuvenator contains many mineral oils to supply the missing components of aged bitumen. The mineral oils could recover the performance of aged bitumen go through a long-term aging process. However, the mineral oils are easy to volatilize at higher recycling temperature. The higher volatilization will reduce the effect of rejuvenator and limit proportion of reclaimed asphalt pavement (RAP) in recycled asphalt mixture (RAP contents less than 30\%). The main components of vegetable oil are straight chain higher fatty acids and glycerides. The esters of straight chain higher fatty acids and glycerol are not volatile at high temperature. Therefore, they can be used to recover the micro chemical composition of bitumen and a change in colloidal stability of asphaltene. In this research, two newly kinds of bitumen rejuvenator were developed by replacing mineral oil with waste cooking corn and soybean oil. The two kinds of vegetable and a mineral bitumen rejuvenators were utilized to recover aged bitumen with $2-10 \%$ by weigh. The objectives of the research are evaluating the rheological properties, high temperature and fatigue performance of the recovered bitumen. The Dynamic Shear Rheometer Test and Rotational Viscosity Test were conducted according to the AASHTO and ASTM standards. Additionally, the crack resistance of bitumen was evaluated by using the bending beam rheometer (BBR) test at -12 and $-18^{\circ} \mathrm{C}$. The result of laboratory test and statistical analysis of ANOVA showed that the vegetable oil rejuvenators effectively reduce the viscosity and stiffness of aged bitumen. It will improve both the fatigue resistance and low temperature crack resistance. In addition, when the content of vegetable oil is higher, the rejuvenating agent can make the recovered bitumen have lower viscosity and stiffness. Considering that the rutting resistance under high temperature, it is suggested that 6 and $8 \%$ vegetable oil be used to recover the aged bitumen.

Keywords: aged bitumen, laboratory evaluation, rejuvenating agent, temperature sensitive, vegetable oil

\section{INTRODUCTION}

In recent years, with more and more pavement reconstruction and maintenance projects have been conducted in China, hundred millions of tons of reclaimed asphalt pavement (RAP) materials are produced every year (West and Willis, 2013). RAP as a kind of construction waste, if not properly treated, it will not only occupy land resources, but also pollute soil and groundwater, 
causing irreparable damage to the environment (West and Willis, 2013). The hot mix recycling asphalt technology, by using RAP instead of virgin mineral aggregates and bitumen, has great advantages in solving RAP accumulation, reducing natural aggregates and bitumen consumption (Huang et al., 2005).

At present, due to the performance of Recycled Asphalt Concrete (RAC), the proportion of RAP in hot mix RAC in China is generally less than 30\% (Garciaa et al., 2010). However, in order to improve the economic and environmental benefits, the trend of adding more RAP materials in the production of recycling asphalt mixture is more and more obvious (Holleran et al., 2006). In order to the same road performance of hot mix recycling asphalt mixture with the virgin asphalt mixture, the aged bitumen in RAP must be recovered by using rejuvenator and the gradation of aggregates shall meet the design criteria (Widyatrnoko, 2003; Romera et al., 2006; Dony et al., 2013). The characteristics of rejuvenators play a key role, because it shall be able to recover the properties of aged bitumen during the manufacturing of the RAC. According to Kallas (1984) and Shen et al. (2009), the rheological properties of bitumen deteriorate during the aging process for two main mechanisms: a change in the micro chemical composition of bitumen and a change in colloidal stability of asphaltene.

The traditional rejuvenators usually contain heavy fuel oils to supply the light oil component of bitumen which decreases throughout a long-term aging process (Leandri et al., 2012; Zargar et al., 2012). Nonetheless, the heavy fuel oils can easily volatilize at a high recycling temperature (above $180^{\circ} \mathrm{C}$ ), leading to the limited proportion of RAP materials used in recycled asphalt mixture (with recycling rates less than $30 \%$ ). There have been a great number of researches in recent years on developing the highly effective aged bitumen rejuvenators to improve the recycling rate in the RAC (Anderson and Bonaquist, 2011; Navaro et al., 2012; Ali et al., 2013; Miliutenko et al., 2013).

Similar to the light oil component, the main components of vegetable oil are straight chain higher fatty acids and glycerides. The esters of straight chain higher fatty acids and glycerol are not volatile at high temperature. According to the bitumen aging and rejuvenation theory, they can be used to recover the aged bitumen. In some US patents, it have been mentioned that the waste cooking oils can be utilized as a rejuvenator for recovering aged bitumen (Corbett, 1975; McGovern, 1987; Lukens, 1998; Takamura, 2008). In addition, Asli et al. (2012) utilized physical properties to investigate the possibility and effects of waste cooking oil as the rejuvenator for aged bituminous pavement. Chen et al. (2014) conducted a laboratory investigation on the high temperature properties of the recovered bitumen with waste cooking oils. The researchers proved that waste cooking oil can be utilized as a rejuvenator to improve the properties of aged bitumen to the similar grade of those of virgin bitumen. However, due to the different properties between vegetable oil and mineral oil, too much or too little percentages of rejuvenator will significantly affect the properties of the recovered asphalt.
The previous researches mainly focused on the applicability of different kinds of waste edible oil to the performance recovery of aging asphalt. However, limited research was found to systematically evaluate the influence of different kinds and different amounts of waste edible oil on the performance of recycled aging asphalt from the aspects of high temperature stability, low temperature crack resistance and fatigue resistance. As a temperature sensitive material, the road performance of recycled asphalt with waste edible oil at high temperature, low temperature and normal temperature still needs in-depth and systematic research.

\section{RESEARCH OBJECTIVE}

The purpose of this study is to use waste edible corn oil and soybean oil instead of mineral oil as bitumen regeneration components, so as to restore the light components in the aged bitumen and improve its rheological properties. The effects of different proportions of waste edible vegetable oil on the road performance of recycled asphalt, such as high temperature deformation resistance, low temperature crack resistance and normal temperature fatigue resistance, were studied.

\section{MATERIALS AND METHODS}

\section{Materials}

The type and composition of organic matter in waste cooking oil are important factors affecting the composition change and performance recovery of aged bitumen. Therefore, the types and compositions of organic compounds in waste edible corn oil and soybean oil were determined by gas chromatographymass spectrometry (GCMs), as shown in Table 1. Based on the composition of a commercial asphalt rejuvenator, two kinds of vegetable oil-based asphalt rejuvenators were developed by using waste edible vegetable oil instead of mineral oil.

The control virgin bitumen was Superpave ${ }^{\mathrm{TM}}$ PG 64-22 sample in this study. The Aged asphalt was extracted from RAP material obtained from a construction site near Beijing, China. The performance indexes of original asphalt and aged asphalt are shown in Table 2.

TABLE 1 | Chemical properties of used cooking oil in this study.

\begin{tabular}{lcc}
\hline Chemical compound & Corn oil (\%) & Soybean oil (\%) \\
\hline Hexadecanoic acid, methyl ester & 10.23 & 7.97 \\
Pentadecanoic acid & 2.41 & 0.95 \\
9,12-Octadecadienoic acid, methyl ester & 38.19 & 39.21 \\
9-Octadecadienoic acid(Z), methyl ester & 34.6 & 31.42 \\
6-Octadecadienoic acid, methyl ester(Z) & 1.23 & 1.46 \\
Octadecanoic acid, methyl ester & 3.95 & 3.71 \\
9,12-Octadecadienoic acid(Z,Z) & 8.08 & 13.9 \\
(Z)6,(Z)9-Pentadecadien-1-ol & 0.95 & 0.76 \\
Tetracosanoic acid, methyl ester & 0.24 & 0.32 \\
Docosanoic acid, methyl ester & 0.12 & 0.3 \\
Total & 100 & 100
\end{tabular}


TABLE 2 | The properties of virgin and aged bitumen.

\begin{tabular}{lccc}
\hline Test items & Standard & PG 64-22 & Aged bitumen \\
\hline $\begin{array}{l}\text { Penetration }(0.1 \mathrm{~mm}) \\
\text { at } 25^{\circ} \mathrm{C}\end{array}$ & ASTM D5 & 72 & 20.8 \\
Softening point $\left({ }^{\circ} \mathrm{C}\right)$ & ASTM D36 & 46 & 60.8 \\
Ductility $(\mathrm{cm})$ at $15^{\circ} \mathrm{C}$ & ASTM D113 & 115 & 8.9 \\
Rotational viscosity & ASTM D4402 & 405.5 & 1,079 \\
$\left(\mathrm{mPa}\right.$ ) at $135^{\circ} \mathrm{C}$ & & & \\
G* $/$ sin $\delta(\mathrm{kPa})$ & AASHTO T315 & 1.325 at $64^{\circ} \mathrm{C}$ & 1.404 at $82^{\circ} \mathrm{C}$ \\
Stiffness $(\mathrm{MPa})$ & AASHTO T313 & 188 at $-12^{\circ} \mathrm{C}$ & 269 at $0^{\circ} \mathrm{C}$ \\
m-value & AASHTO T313 & 0.416 at $-12^{\circ} \mathrm{C}$ & 0.358 at $0^{\circ} \mathrm{C}$ \\
\hline
\end{tabular}

\section{Experimental}

The detailed experimental scheme includes the preparation of recovered asphalt, characterization of basic physical properties, high temperature viscosity, high temperature stability, low temperature crack resistance and fatigue resistance, indicated in Figure 1.
A commercial asphalt rejuvenator (based on mineral oil, referred to as $\mathrm{M}$ ) and two developed rejuvenators (based on corn oil, referred to as C, based on soybean oil, referred to as S) were added into the aged asphalt according to the weight ratio of $2-10 \%$, the regeneration process was shown in Figure 2. The regeneration temperature was $135^{\circ} \mathrm{C}$, and the mixing speed was $1,000 \mathrm{rpm}$ for $1 \mathrm{~h}$.

\section{Fundamental Properties}

The physical properties of recovered asphalt are evaluated by the following tests:

- Penetration test at $25^{\circ} \mathrm{C}$ in accordance with standard ASTM D5.

- Softening point test in accordance with standard ASTM D36.

- Ductility test in accordance with standard ASTM D113.

High Temperature Viscosity Test

Rotational viscosity test in accordance with standard ASTM D4402 is introduced by the Superpave ${ }^{\mathrm{TM}}$ to determine the

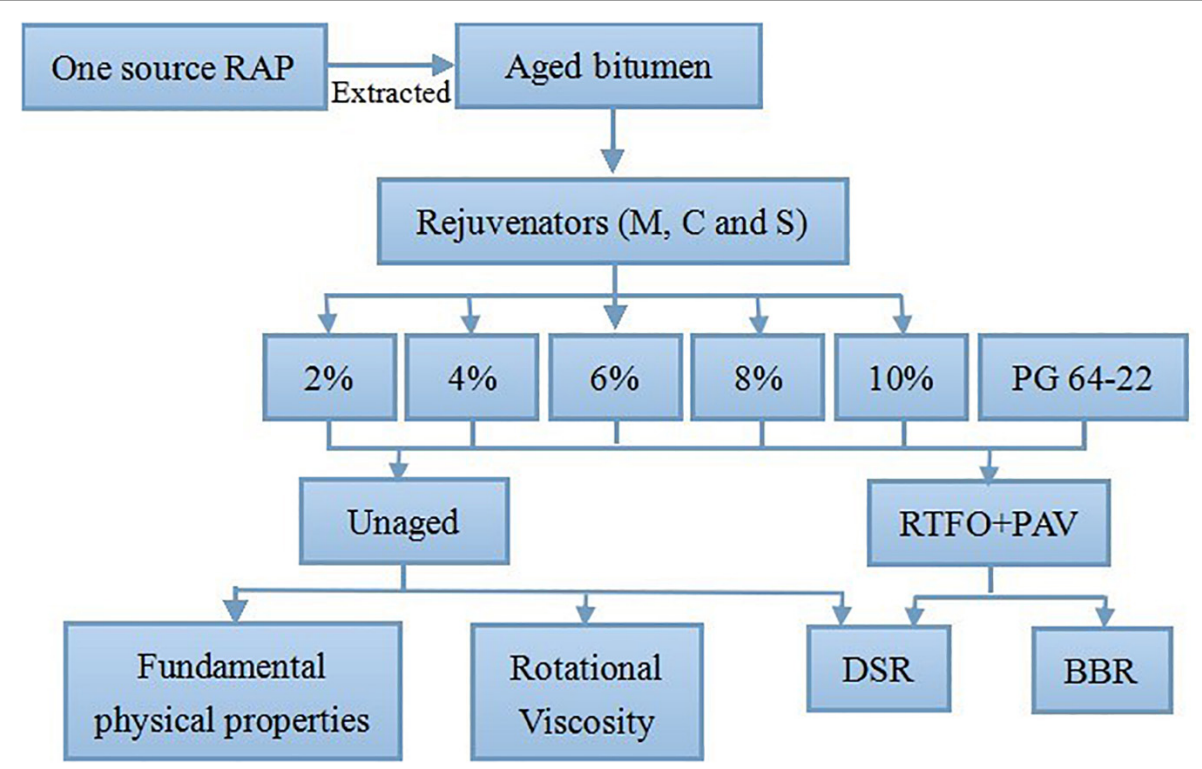

FIGURE 1 | Experimental microphotographs plan for the recovered bitumen tests.

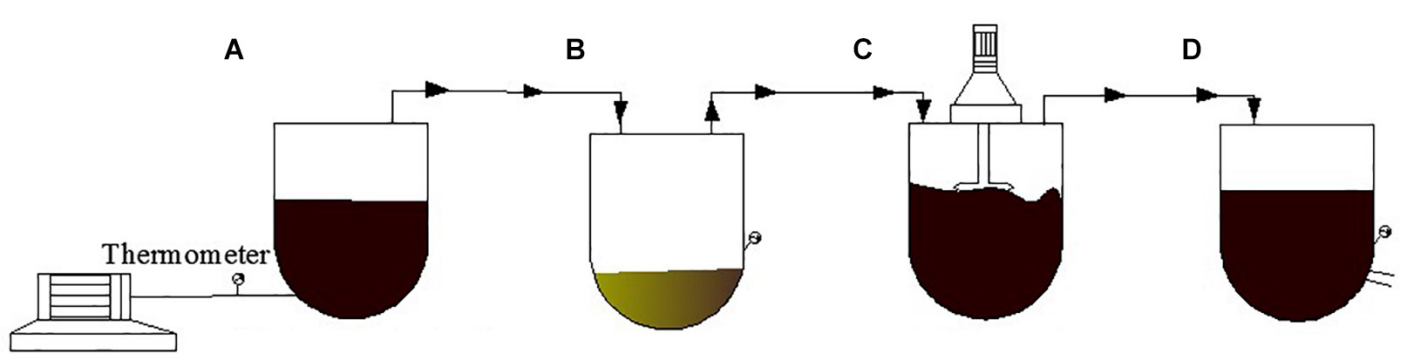

FIGURE 2 | The recycling process of aged bitumen. (A) Preheating device for aged asphalt; preheating temperature $135^{\circ} \mathrm{C}$. (B) Regenerative storage equipment; storage temperature $25^{\circ} \mathrm{C}$. (C) High speed shear mixer; mixing speed was $1,000 \mathrm{rpm}$ for $1 \mathrm{~h}$. (D) Static device of recycled asphalt; static temperature $135^{\circ} \mathrm{C}$. 
mix and compact temperatures based on the viscosity values at an elevated temperature. In this study, recovered asphalt samples were thermally stabilized for $1 \mathrm{~h}$ at five different temperatures $\left(120-180^{\circ} \mathrm{C}\right)$. The test torque is $45 \%$ and the speed is $20 \mathrm{rpm}$.

\section{Dynamic Shear Rheometer (DSR) Test}

According to AASHTO T315, DSR was used to measure the rheological properties of each recovered asphalt sample at different temperatures. In this study, a $25 \mathrm{~mm}$ diameter plate with a gap of $1 \mathrm{~mm}$ was used to measure the complex shear modulus $\left(\mathrm{G}^{*}\right)$ and phase angle $(\delta)$ of all asphalts to calculate the rutting factor $\left(\mathrm{G}^{*} / \sin \delta\right)$. In addition, the asphalt aged by RTFO and PAV was measured with a plate with a diameter of $8 \mathrm{~mm}$ and a gap of $2 \mathrm{~mm}$, and the fatigue factor $\left(\mathrm{G}^{*} \sin \delta\right)$ was calculated. Finally, the high temperature performance and fatigue performance of recovered asphalt were evaluated by using these two factors.

\section{Bending Beam Rheometer (BBR) Test}

According to AASHTO T313, bending beam rheometer (BBR) test was used to evaluate the stiffness of recycled asphalt at -12 and $-18^{\circ} \mathrm{C}$.

In order to further verify, the viscosity of each asphalt sample was tested for three times, and the effects of main influencing factors such as temperature, type of rejuvenating agent and the content of rejuvenating agent on the properties of recycled asphalt were evaluated by DSR and BBR characteristic tests and ANOVA analysis results.

\section{RESULTS AND DISCUSSION}

\section{Fundamental Properties}

Figures 3-5 shows the test results of fundamental properties such as penetration, softening point and ductility of original PG 64-22,

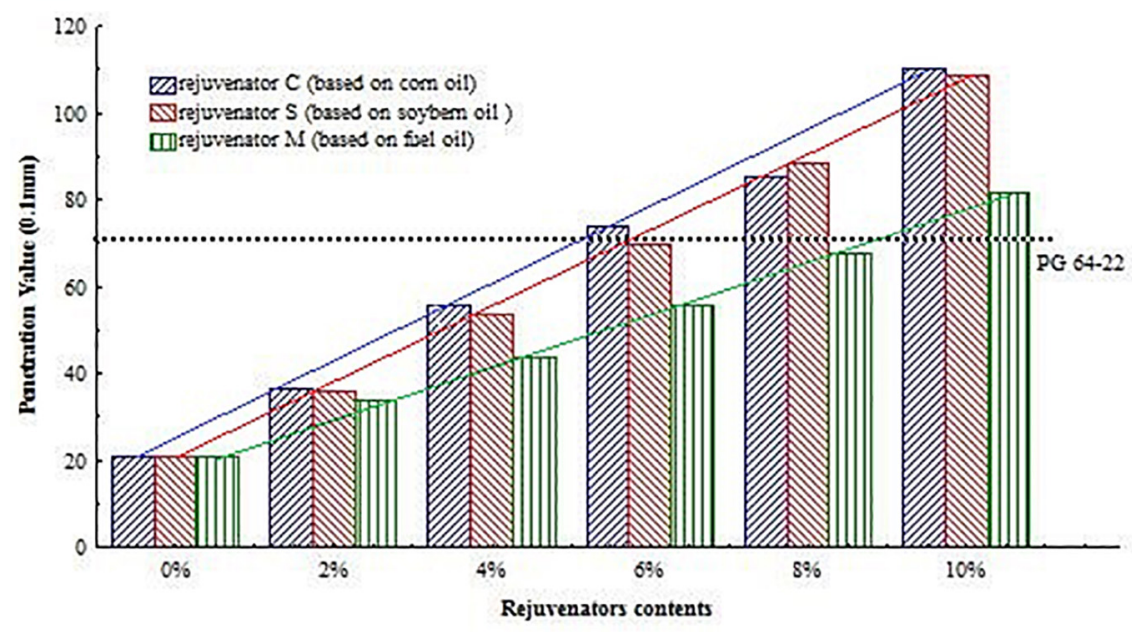

FIGURE 3 | Relationship of penetration value and different rejuvenators.

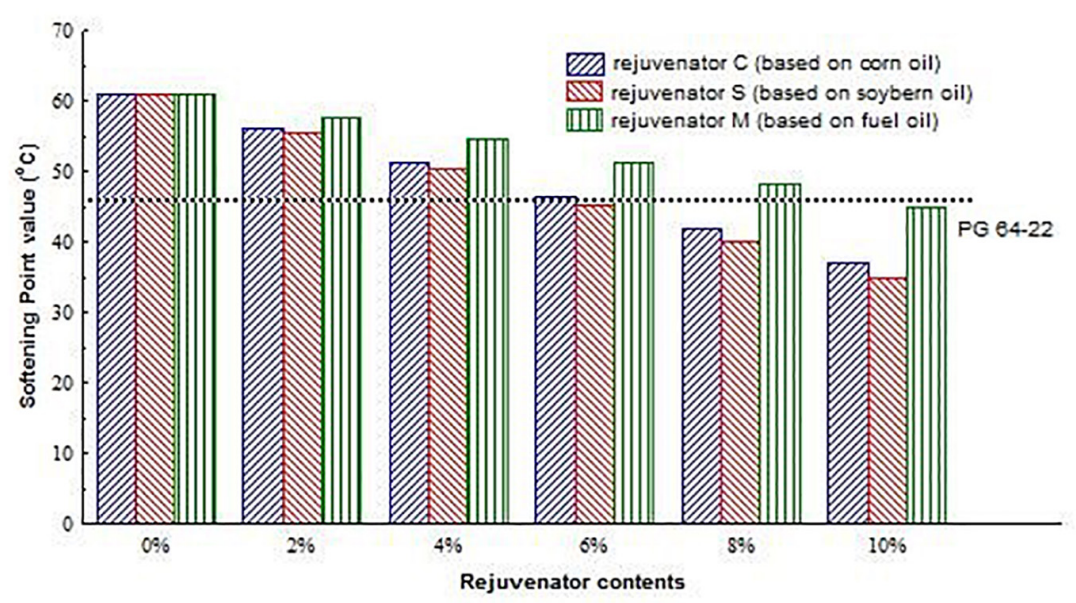

FIGURE 4 | Relationship of softening point value and different rejuvenators. 


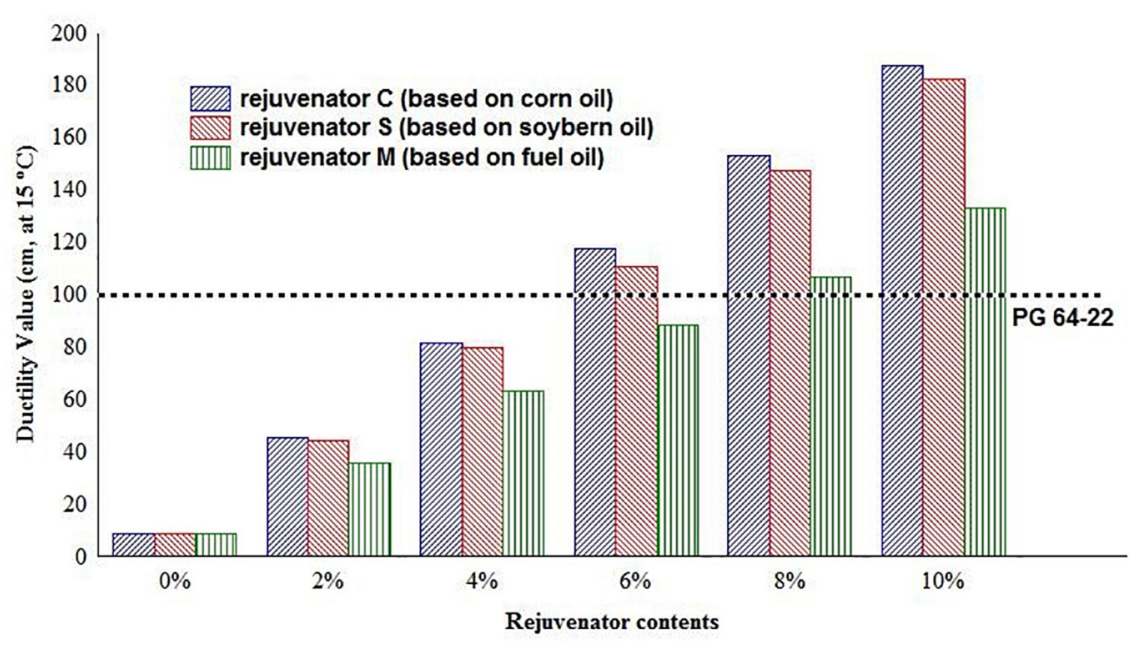

FIGURE 5 | Relationship of ductility value and different rejuvenators.

for the aged asphalt (extracted from RAP material) and recovered asphalt with different types and contents of rejuvenators.

It can be seen from Figure 3 that the penetration increases linearly with the increase of rejuvenator content in aged asphalt. The penetration rate of asphalt with $C$ and $S$ is higher than that of asphalt with $M$ the same content. This shows that the rejuvenator efficiency of the regeneration agent based on waste edible vegetable oil is higher, and it can reduce the hardness of the aged asphalt more effectively.

When the content of vegetable oil-based rejuvenator is $6 \%$ and mineral oil-based is $8 \%$, the penetration of recovered asphalt is restored to the standard of original asphalt PG64-22. In addition, through the statistical analysis of the experimental results, the average coefficient of variation of recovered asphalt with vegetable oil-based rejuvenator is $0.32 \%$, which is $60 \%$ lower than that with mineral oil-based rejuvenator $(C V=0.56 \%)$. It is proved that the workability of recovering aged asphalt with vegetable oil-based rejuvenator is obviously better than that of recovering aged asphalt with mineral oil-based rejuvenator.

The softening point test results of different recovered asphalt are shown in Figure 4. According to the test results, the softening point of recovered asphalt decreases significantly with the increase of rejuvenator content in aged asphalt. When the amount of vegetable oil-based rejuvenator is $6 \%$ and the amount of mineral oil-based rejuvenator is $10 \%$, the softening point of recovered asphalt will meet to the standard of original asphalt PG 64-22. In addition, the average variability of the test results of vegetable oil-based recovered asphalt is less than that of mineral oil-based recovered asphalt, which is consistent with the statistical analysis of penetration test results.

The ductility test results of different recovered asphalt are shown in Figure 5. The test results show that the ductility of recovered asphalt increases significantly with the increase of rejuvenator content in aged asphalt. When the content of vegetable oil-based rejuvenator is $6 \%$ and the content of mineral oil-based rejuvenator is $8 \%$, the ductility of recovered asphalt reaches the original asphalt PG 64-22 standard. It shows that the rejuvenator based on waste edible vegetable oil can improve the plasticity of aged asphalt more effectively. In addition, the average variability of the test results of vegetable oil-based recovered asphalt is less than that of mineral oil-based recovered asphalt, which is consistent with the statistical analysis of penetration and softening point test results. Compared with mineral oil, the vegetable oil has high temperature stability, and the volatility of vegetable oil is reduced during the process of recycling, so the amount of vegetable oil-based rejuvenators is reduced.

\section{High Temperature Viscosity}

Viscosity index is used to evaluate the flow performance of asphalt at high temperature. And it is used to determine the workability in the process of production and construction of asphalt mixture. In the process of hot recycling of asphalt mixture, similar to the production of traditional hot mix asphalt mixture, the appropriate production and recycling temperature should be determined according to the relationship curve between viscosity and temperature of asphalt.

The high temperature viscosity test results of different recovered asphalt are shown in Figure 6. The type and content of rejuvenator have an obvious effect on the viscosity of recovered asphalt. When the amount of vegetable oil-based rejuvenator is $6 \%$ and the amount of mineral oil-based rejuvenator is $8 \%$, the high temperature viscosity of recovered asphalt reaches the standard of original bitumen PG 64-22. The results show that vegetable oil-based rejuvenator can effectively reduce the viscosity of aged asphalt and disperse asphaltene in aged asphalt (Lu and Isacsson, 2009).

In order to quantify the relationship between the influencing factors and the viscosity of recovered asphalt, the linear regression method was used to analyze the viscosity and temperature of recovered asphalt. The expression is as follows (Specht et al., 2007; Dessouky et al., 2011).

$$
\log (V)=a \cdot T+b
$$



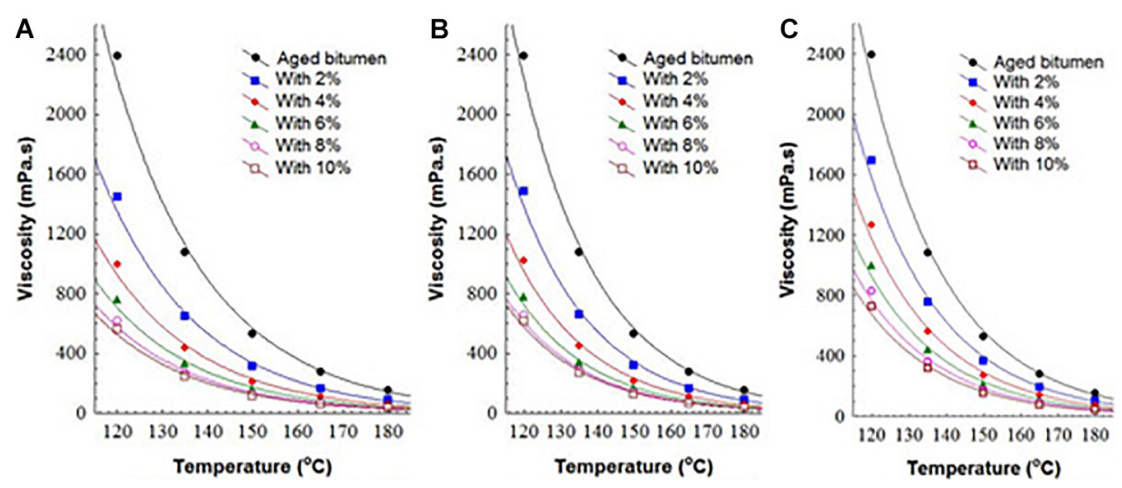

FIGURE 6 | Viscosity of recovered bitumen with C, S, and M rejuvenators at different temperature. (A) Rejuvenator C (based on corn oil). (B) Rejuvenator S (based on soybean oil). (C) Rejuvenator M (based on fuel oil).

TABLE 3 | Regression parameters for viscosities of recovered bitumen.

\begin{tabular}{|c|c|c|c|c|c|c|c|c|c|}
\hline Contents (\%) & \multicolumn{3}{|c|}{ Rejuvenator C } & \multicolumn{3}{|c|}{ Rejuvenator S } & \multicolumn{3}{|c|}{ Rejuvenator M } \\
\hline 4 & -0.0204 & 5.4088 & 0.998 & -0.0203 & 5.4171 & 0.998 & -0.0202 & 5.4954 & 0.998 \\
\hline 6 & -0.0205 & 5.3118 & 0.998 & -0.0205 & 5.3187 & 0.997 & -0.0203 & 5.4091 & 0.996 \\
\hline 8 & -0.0206 & 5.2378 & 0.997 & -0.0206 & 5.2577 & 0.996 & -0.0204 & 5.3423 & 0.996 \\
\hline
\end{tabular}

Wherein, $\mathrm{V}$ (viscosity of the recovered bitumen, $\mathrm{mPa} . \mathrm{s}$ ), $\mathrm{T}$ (temperature, ${ }^{\circ} \mathrm{C}$ ), a and $\mathrm{b}$ (the regression parameters).

The two regression parameters "a" and " $b$ " are of great significance to characterize the high temperature viscosity of recovered asphalt. Where a represents the slope of the equation, which represents the rate of viscosity change of recycled asphalt with temperature. When "a" value is larger, the temperature sensitivity of recovered asphalt increases.

The results of regression parameters between viscosity and temperature of different recovered asphalt are shown in Table 3. The correlation coefficient reaches or exceeds 0.99, which indicates that equation (1) can well fit the relationship between viscosity and temperature of recovered asphalt. Although the increase of parameters " $a$ " and "b" will help to reduce the viscosity of aged asphalt, if the parameter "a" is too high, the temperature sensitivity of recovered asphalt will be improved, which is not conducive to the recovered asphalt to obtain higher viscosity to improve the rutting resistance at service temperature. Therefore, corresponding to the original asphalt PG 64-22, the regression parameters "a" and "b" of recovered asphalt should be 0.02 and 5.41 , respectively. Under this standard, the amount of vegetable oil-based rejuvenator should be $4 \%$, while the amount of mineral oil-based rejuvenator should be $8 \%$.

In this study, the statistical analysis of variance (ANOVA) was used to analyze the three factors that affect the high temperature viscosity of recovered asphalt, including the type of rejuvenator, content and temperature. The results of variance analysis show that the viscosity of recycled asphalt is significantly affected by the type, dosage and temperature of recycled agent, as shown in Table 4. In addition, a single factor analysis of variance (ANOVA) was used to evaluate the influence of blending ratio of vegetable oil-based and mineral oil-based rejuvenator on the viscosity of recovered asphalt. The analysis results are shown in Table 5. The results of single factor analysis of variance show that the influence of mineral oilbased rejuvenator on the viscosity of recovered asphalt is lower than that of vegetable oil-based, which means that vegetable oil-based rejuvenator plays a stronger role in reducing viscosity and mixing resistance. At the same time, the test results show that the influence of vegetable oil-based rejuvenator in the range of $0-8 \%$ on the viscosity of recycled asphalt is more significant than that in the range of $8-10 \%$, which means that the effect of excessive waste edible vegetable oil-based rejuvenator on degrading the viscosity of aged asphalt and reducing the mixing resistance of mixture is reduced. Therefore, it is not recommended to use more than $8 \%$ vegetable

TABLE 4 | Two-factor ANOVA on the viscosity of recovered bitumen $(\alpha=0.05)$.

\begin{tabular}{lcccccc}
\hline Rejuvenators & $\begin{array}{c}\text { Source of } \\
\text { variation }\end{array}$ & $\begin{array}{c}\text { SS } \\
(\mathbf{m P a} . \mathbf{s})\end{array}$ & $\mathbf{d f}$ & $\begin{array}{c}\text { MS } \\
(\mathbf{m P a} \text {.s) }\end{array}$ & $\mathbf{F}$ & $\boldsymbol{P}$-value \\
\hline $\mathrm{C}$ & Temperature & 4525.511 & 4 & 1131.283 & 16.004 & $5 \mathrm{E}-06$ \\
& Contents & 1698.847 & 5 & 340.486 & 4.804 & 0.0048 \\
$\mathrm{~S}$ & Temperature & 4710.512 & 4 & 1205.682 & 17.277 & $3 \mathrm{E}-06$ \\
& Contents & 1639.210 & 5 & 482.397 & 4.809 & 0.0047 \\
$\mathrm{M}$ & Temperature & 6132.201 & 4 & 1533.548 & 26.475 & $1 \mathrm{E}-06$ \\
& Contents & 1396.557 & 5 & 279.621 & 4.823 & 0.0047
\end{tabular}


TABLE 5 | One-factor rejuvenator contents ANOVA on viscosity of recovered bitumen $(\alpha=0.05)$.

\begin{tabular}{|c|c|c|c|c|c|c|}
\hline \multirow[t]{2}{*}{ Rejuvenators contents } & \multicolumn{2}{|c|}{ Rejuvenator C } & \multicolumn{2}{|c|}{ Rejuvenator S } & \multicolumn{2}{|c|}{ Rejuvenator M } \\
\hline & $\mathbf{F}$ & $P$-value & $\mathbf{F}$ & $P$-value & $\mathbf{F}$ & $P$-value \\
\hline $0-2 \%$ & 21.282 & 0.000388 & 20.154 & 0.002074 & 17.018 & 0.006440 \\
\hline $2-4 \%$ & 19.462 & 0.003078 & 19.024 & 0.003702 & 16.541 & 0.007062 \\
\hline $4-6 \%$ & 16.799 & 0.006727 & 16.698 & 0.006859 & 12.685 & 0.011695 \\
\hline $6-8 \%$ & 10.321 & 0.014182 & 9.722 & 0.014770 & 10.541 & 0.013962 \\
\hline $8-10 \%$ & 2.7153 & 0.081243 & 2.581 & 0.111243 & 8.254 & 0.019338 \\
\hline
\end{tabular}
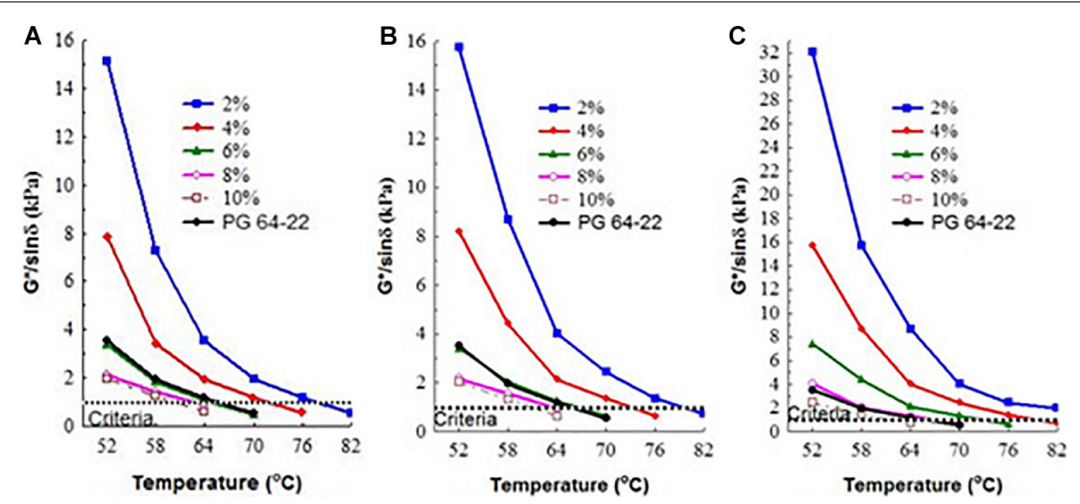

FIGURE 7 | Rutting resistance factors for the recovered bitumen with different contents of C, S, and M rejuvenators. (A) Rejuvenator C (based on corn oil). (B) Rejuvenator S (based on soybean oil). (C) Rejuvenator M (based on fuel oil).

oil-based rejuvenator to recover the performance of aged asphalt, considering that the high content of rejuvenator will increase the cost of asphalt recycling.

\section{Rutting Resistance Factor (G*/sin $\delta)$}

Rutting is a common disease of asphalt pavement caused by irrecoverable deformation accumulation during the use of asphalt mixture. The high temperature stability of asphalt mixture is directly related to the rheological properties of asphalt. When the rutting factor $\mathrm{G}^{*} / \sin \delta$ of asphalt is higher, the asphalt mixture will have good rutting resistance.

Figure 7 shows the effect of type and content of rejuvenator on rutting resistance factor of recovered asphalt at different temperatures. The results show that the anti-rutting coefficient of recovered asphalt decreases significantly with the increase of rejuvenator content. At the same temperature, the $\mathrm{G}^{*} / \sin \delta$ value of vegetable oil-based recovered asphalt is lower than that of mineral oil-based recovered asphalt. When the content of vegetable oil-based regenerant is $6 \%$ and the content of mineral oil-based regenerant is more than $8 \%$, the $\mathrm{G}^{*} / \sin \delta$ value of recovered asphalt sample is similar to that of virgin asphalt (PG 64-22). In addition, in the temperature range of $64-70^{\circ} \mathrm{C}$, the rutting resistance factor of recovered asphalt samples with excessive waste edible vegetable oil rejuvenator (more than 6\%) is less than $1.0 \mathrm{kPa}$, which means that the high temperature resistance of recovered asphalt is one grade lower than that of virgin asphalt PG 64-22.

The variance analysis method (ANOVA) is also used to examine the influence of different factors on the rutting resistance factor of recovered asphalt, as shown in Table 6. It can be seen from the table that the influence of type, content and temperature on rutting resistance factor of recovered asphalt is very significant. In addition, a single factor analysis of variance is used to evaluate the influence of different types of rejuvenators on $\mathrm{G}^{*} / \sin \delta$ of recovered asphalt, as shown in Table 7. The results show that the influence of mineral oil-based rejuvenator on $\mathrm{G}^{*} / \sin \delta$ of recovered asphalt is lower than that of vegetable oil-based rejuvenator in the range of $0-10 \%$. At the same time, the significant effect of vegetable oil-based regenerant decreased with the increase of content, and there was no significant difference in the range of $8-10 \%$.

\section{Fatigue Resistance Factor (G* $\sin \delta)$}

The fatigue resistance of asphalt concrete refers to its ability to bear repeated bending and tension without fracture. The fatigue resistance of asphalt mixture is directly related to the rheological properties of asphalt at room temperature. When the fatigue resistance factor $\mathrm{G}^{*} \sin \delta$ of asphalt is higher, asphalt mixture has better fatigue resistance.

TABLE 6 | Two-factor ANOVA on the $\mathrm{G}^{\star} / \mathrm{sin} \delta$ of recovered bitumen $(\alpha=0.05)$.

\begin{tabular}{lcccccc}
\hline Rejuvenators & $\begin{array}{c}\text { Source of } \\
\text { variation }\end{array}$ & $\begin{array}{c}\text { SS } \\
(\mathbf{m P a} \text {.s) }\end{array}$ & $\mathbf{d f}$ & $\begin{array}{c}\text { MS } \\
(\mathbf{m P a} \text {.s) }\end{array}$ & $\mathbf{F}$ & $\boldsymbol{P}$-value \\
\hline C & Temperature & 4467.415 & 6 & 241.212 & 19.64 & 0.005412 \\
& Contents & 4752.665 & 5 & 293.846 & 26.28 & 0.005541 \\
S & Temperature & 4512.387 & 6 & 344.621 & 20.29 & 0.006338 \\
& Contents & 4022.520 & 5 & 362.513 & 29.28 & 0.006732 \\
M & Temperature & 3183.355 & 6 & 534.984 & 38.16 & 0.013609 \\
& Contents & 2792.741 & 5 & 560.520 & 40.16 & 0.013723
\end{tabular}


TABLE 7 | One-factor rejuvenator contents ANOVA on $\mathrm{G}^{*} / \sin \delta$ of recovered bitumen $(\alpha=0.05)$.

\begin{tabular}{|c|c|c|c|c|c|c|}
\hline \multirow[t]{2}{*}{ Rejuvenators contents } & \multicolumn{2}{|c|}{ Rejuvenator C } & \multicolumn{2}{|c|}{ Rejuvenator S } & \multicolumn{2}{|c|}{ Rejuvenator M } \\
\hline & $\mathbf{F}$ & $P$-value & $\mathbf{F}$ & $P$-value & $\mathbf{F}$ & $P$-value \\
\hline $0-2 \%$ & 41.257 & 0.000407 & 40.129 & 0.000624 & 37.058 & 0.002102 \\
\hline $2-4 \%$ & 37.729 & 0.003232 & 37.879 & 0.002998 & 36.019 & 0.004698 \\
\hline $4-6 \%$ & 35.612 & 0.007063 & 35.223 & 0.007408 & 28.419 & 0.009748 \\
\hline $6-8 \%$ & 25.348 & 0.014891 & 23.364 & 0.013952 & 30.795 & 0.010219 \\
\hline $8-10 \%$ & 10.854 & 0.125305 & 10.653 & 0.100142 & 19.018 & 0.021078 \\
\hline
\end{tabular}
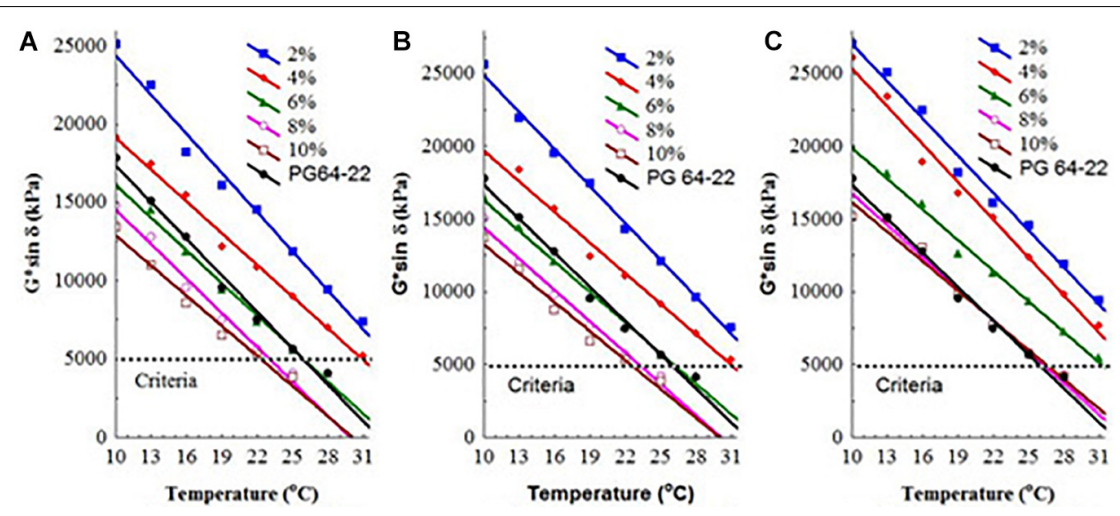

FIGURE 8 | Fatigue factors for the recovered bitumen with different contents of C, S, and M rejuvenators. (A) Rejuvenator C (based on corn oil). (B) Rejuvenator S (based on soybean oil). (C) Rejuvenator M (based on fuel oil).

The fatigue resistance factor test results of vegetable oilbased recovered asphalt and mineral oil-based recovered asphalt at different temperatures are shown in Figure 8. The figure shows the change rule of fatigue resistance factor of different types of recovered asphalt. The test results show that the fatigue resistance factor of recovered asphalt increases continuously with the increase of rejuvenator content. At the same temperature, the $\mathrm{G}^{*} \sin \delta$ value of recovered asphalt with vegetable oil is lower than that of recovered asphalt with mineral oil. It is proved that the fatigue resistance of vegetable oil based recovered asphalt is better than that of mineral oil based. When the amount of vegetable oil rejuvenator reaches $6 \%$ and mineral oil rejuvenator reaches $10 \%$, the $\mathrm{G}^{*} \sin \delta$ value of recovered asphalt is similar to that of virgin asphalt (PG 64-22). In addition, at the temperature range of $22-25^{\circ} \mathrm{C}$, when the amount of vegetable oil-based rejuvenator reaches $8 \%$, the fatigue resistance factor of recovered asphalt is less than 5,000 $\mathrm{kPa}$. This means that the fatigue resistance of recovered asphalt is one grade higher than that of virgin asphalt.

The results of variance analysis (ANOVA) of fatigue resistance factor of recovered asphalt are shown in Table 8. It can be seen from the table that the type of rejuvenator, content of rejuvenator and temperature will significantly affect the fatigue resistance factor of recovered asphalt. In this study, a single factor analysis of variance was used to evaluate the influence of vegetable oil and mineral oil-based rejuvenator on the fatigue resistance factor $\left(G^{*} \sin \delta\right)$ of recovered asphalt, as shown in Table 9. The results of variance analysis show that vegetable oil-based rejuvenator has more significant effect on the fatigue resistance factor of recovered asphalt. In addition, with the increase of the amount of vegetable oilbased rejuvenator, the influence of fatigue resistance factor of recovered asphalt decreases. When the amount of vegetable oilbased rejuvenator is more than $8 \%$, the effect of rejuvenator on the fatigue factor of recovered asphalt tends to be consistent. Therefore, from the perspective of engineering economy, it is suggested that the amount of vegetable oil-based rejuvenator should not exceed $8 \%$.

\section{Low Temperature Stiffness}

In order to evaluate the low-temperature performance of recovered asphalt, this research uses BBR test to determine the creep stiffness of vegetable oil-based recovered asphalt and mineral oil-based recovered asphalt at -12 and $-18^{\circ} \mathrm{C}$ temperature, as shown in Figure 9 (Xiao et al., 2011). The test results of low temperature creep stiffness show that the low temperature stiffness of recovered asphalt decreases

TABLE 8 | Two-factor ANOVA on the $\mathrm{G}^{*} \sin \delta$ of recovered bitumen $(\alpha=0.05)$.

\begin{tabular}{lcccccc}
\hline Rejuvenators & $\begin{array}{c}\text { Source of } \\
\text { variation }\end{array}$ & $\begin{array}{c}\text { SS } \\
(\mathbf{m P a} \text {.s) }\end{array}$ & df & $\begin{array}{c}\text { MS } \\
\text { (mPa.s) }\end{array}$ & F & P-value \\
\hline C & Temperature & 7034.484 & 7 & 102.254 & 26.288 & 0.001747 \\
& Contents & 4096.652 & 4 & 100.324 & 19.643 & 0.001451 \\
S & Temperature & 7321.741 & 7 & 106.554 & 23.272 & 0.002724 \\
& Contents & 4262.684 & 4 & 104.798 & 22.842 & 0.002421 \\
M & Temperature & 9893.552 & 7 & 141.151 & 21.707 & 0.005173 \\
& Contents & 4975.451 & 4 & 124.458 & 19.103 & 0.005088
\end{tabular}


greatly with the increase of the amount of rejuvenator. This shows that the rejuvenator can significantly improve the flexibility of recovered asphalt, so as to improve the low temperature cracking resistance of asphalt pavement. At the reference temperatures of -12 and $-18^{\circ} \mathrm{C}$, when the amount of vegetable oil-based rejuvenator reaches $6 \%$ and mineral oil-based rejuvenator reaches $8 \%$, the low-temperature creep stiffness of recovered asphalt is similar to that of virgin asphalt PG 64-22.
According to the requirements of Superpave specification (AASHTO M320), the low temperature creep stiffness of asphalt should be less than $300 \mathrm{mPa}$, and the stiffness change rate ( $\mathrm{m}$ value) should be greater than 0.3 . When the amount of vegetable oil-based rejuvenator reaches $6 \%$ and mineral oil-based rejuvenator reaches $8 \%$, the creep stiffness of recovered asphalt is similar to that of virgin asphalt, which is less than $300 \mathrm{mPa}$ at $-12^{\circ} \mathrm{C}$. When the amount of vegetable oil-based rejuvenator is more than $8 \%$, the creep stiffness of recovered asphalt will be one

TABLE 9 | One-factor rejuvenator contents ANOVA on $\mathrm{G}^{\star} \sin \delta$ of recovered bitumen $(\alpha=0.05)$.

\begin{tabular}{|c|c|c|c|c|c|c|}
\hline \multirow[t]{2}{*}{ Rejuvenators contents } & \multicolumn{2}{|c|}{ Rejuvenator C } & \multicolumn{2}{|c|}{ Rejuvenator S } & \multicolumn{2}{|c|}{ Rejuvenator M } \\
\hline & $\mathbf{F}$ & $P$-value & $\mathbf{F}$ & $P$-value & $\mathbf{F}$ & $P$-value \\
\hline $2-4 \%$ & 23.877 & 0.00592 & 23.342 & 0.00619 & 21.546 & 0.009043 \\
\hline $4-6 \%$ & 14.678 & 0.01432 & 14.109 & 0.01845 & 19.342 & 0.012423 \\
\hline $6-8 \%$ & 6.452 & 0.021730 & 5.926 & 0.024827 & 12.875 & 0.021234 \\
\hline
\end{tabular}
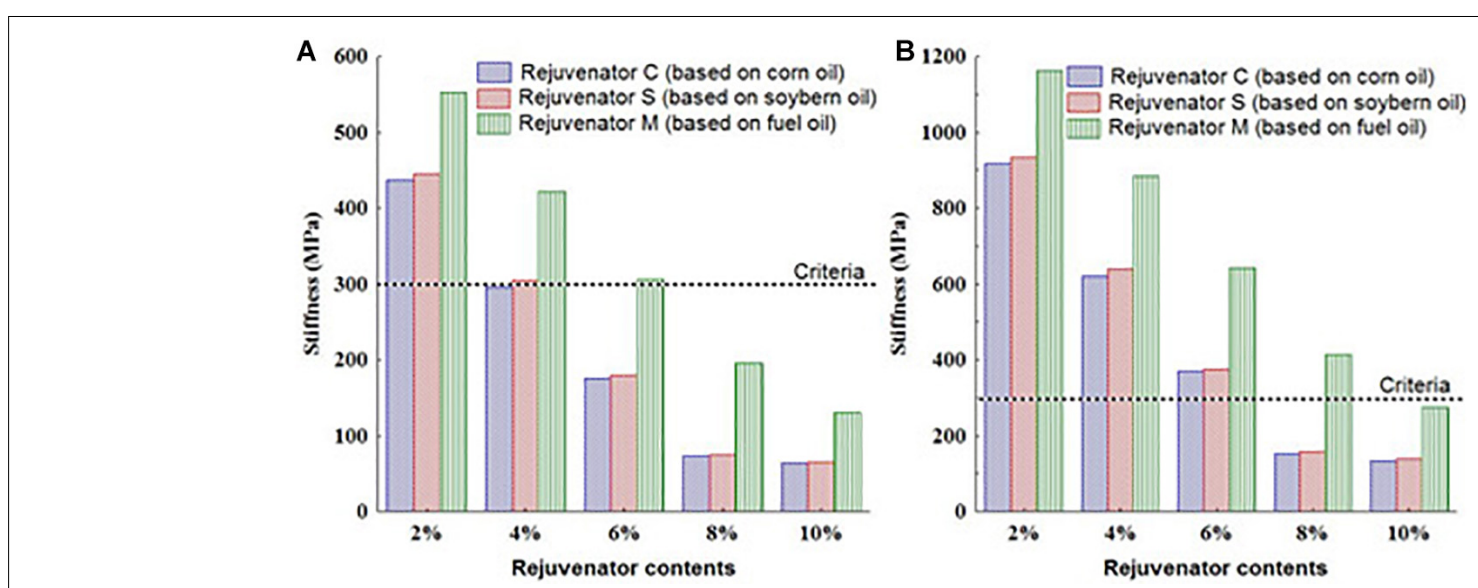

FIGURE 9 | Low temperature stiffness on recovered bitumen at -12 and $-18^{\circ} \mathrm{C}$. (A) Temperature at $-12^{\circ} \mathrm{C}$. (B) Temperature at $-18^{\circ} \mathrm{C}$.

TABLE 10 | Two-factor ANOVA on the low temperature stiffness of recovered bitumen $(\alpha=0.05)$.

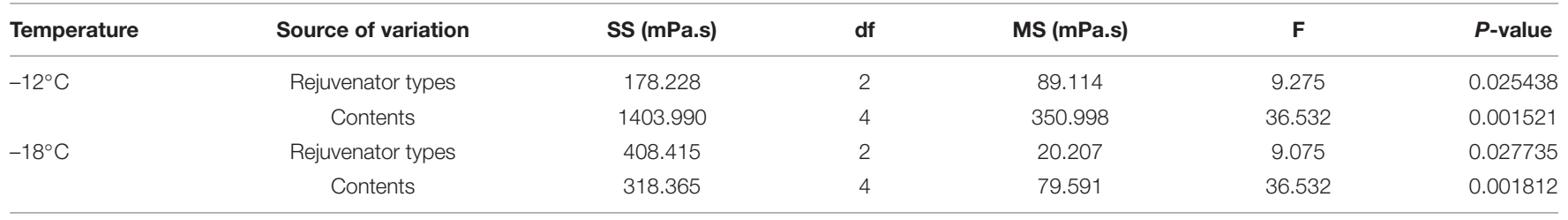

TABLE 11 | One-factor ANOVA on low temperature stiffness of recovered bitumen ( $\alpha=0.05)$.

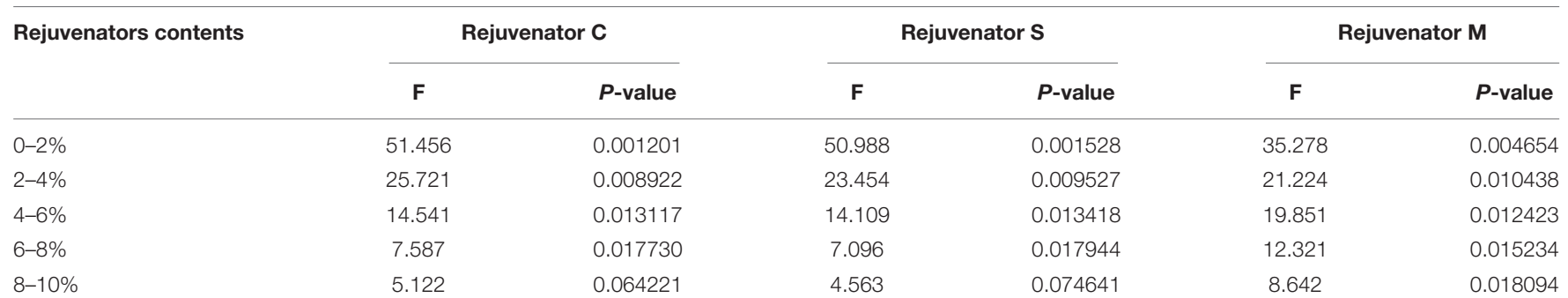


grade higher than that of virgin asphalt, and it is still less than 300 $\mathrm{mPa}$ at $-18^{\circ} \mathrm{C}$.

Variance analysis is also used to evaluate the low temperature creep stiffness of vegetable oil-based recovered asphalt and mineral oil-based recovered asphalt, as shown in Table $\mathbf{1 0}$ and Table 11. From the analysis of variance of low temperature creep, it can be seen that the type of regenerant, content of rejuvenator and temperature all have significant effects on the creep stiffness of recovered asphalt. In the range of $0-10 \%$, the effect of vegetable oil-based rejuvenator on the creep stiffness of recovered asphalt is more significant than that of mineral oil-based rejuvenator. With the increase of the amount of rejuvenator, the significant effect of rejuvenator on the creep stiffness of recovered asphalt gradually decreases. When the amount of vegetable oil-based regeneration was 8 and $10 \%$, the level of significance was consistent. Therefore, it is not recommended to use more than $8 \%$ vegetable oil rejuvenator to recover the low temperature creep stiffness of aged asphalt.

\section{CONCLUSION}

In this study, two vegetable oil-based rejuvenators and one mineral oil-based rejuvenator were used to recovered the aged asphalt. The fundamental properties, high temperature viscosity, rheological properties and low temperature properties of recovered asphalt are systematically evaluated in laboratory. Through the method of variance analysis, the influence of the type of rejuvenator, the content of rejuvenator and temperature on the performance of recovered asphalt is analyzed. The preliminary conclusions are as follows:

(1) According to the results of penetration test, softening point test and ductility test, the fundamental physical properties of vegetable oil-based recovered asphalt have stronger recovery ability. At the same time, the workability of vegetable oil-based recovered asphalt is better than that of mineral oil-based recovered asphalt.

(2) Compared with mineral oil-based rejuvenator, the two kinds of waste edible vegetable oil-based rejuvenator have stronger effect on reducing viscosity and mixing resistance of aged asphalt. This means that using waste edible vegetable oil-based rejuvenator can effectively reduce the recycling temperature.

(3) In addition, when the amount of vegetable oil-based rejuvenator exceeds $8 \%$, the high temperature stability of

\section{REFERENCES}

Ali, H., Mccarthy, L. M., and Welker, A. (2013). Performance of hot in-place recycled Superpave mixture in Florida. Constr. Build. Mater. 49, 618-626. doi: 10.1016/j.conbuildmat.2013.08.043

Anderson, D. A., and Bonaquist, R. (2011). Investigation of Short-Term Laboratory Aging of Neat and Modified Asphalt Binders. NCHRP Report 709. Washington D.C: National Academies Press.

Asli, H., Ahmadinia, E., Zargar, M., and Karim, M. R. (2012). Investigation on physical of waste cooking oil- rejuvenated bitumen binder. Constr. Build. Mater. 37, 398-405. doi: 10.1016/j.conbuildmat.2012.07.042 recovered asphalt will be greatly affected, which cannot meet the standard requirements of PG 64-22.

(4) Compared with the mineral oil-based rejuvenator, the vegetable oil-based rejuvenator is more favorable for recovering the fatigue resistance of aged asphalt. When the amount of waste edible vegetable oil-based rejuvenator is more than $8 \%$, the fatigue resistance of recovered asphalt is even one grade higher than that of virgin asphalt.

(5) The results of BBR test show that the low temperature cracking resistance of recovered asphalt containing more than $8 \%$ waste edible vegetable oil is one grade higher than that of virgin asphalt.

(6) Considering the high temperature stability, low temperature crack resistance and fatigue resistance of asphalt, the value $8 \%$ is recommended as the best amount of vegetable oil-based rejuvenator to recover the aged asphalt.

\section{DATA AVAILABILITY STATEMENT}

The raw data supporting the conclusions of this article will be made available by the authors, without undue reservation.

\section{AUTHOR CONTRIBUTIONS}

ZS was the director of this research. HC, QY, and YT were research students and carried the bitumen test. XL and AZ were researcher collaboration and carried the bitumen test. All authors contributed to the article and approved the submitted version.

\section{FUNDING}

The research was supported by the National Natural Science Foundation of China (Grant Nos. 51778027 and 52078024) and the Beijing Natural Science Foundation (Grant No. 8144042).

\section{ACKNOWLEDGMENTS}

We would like to thank Wing-gun Wong at Hong Kong Road Research Laboratory (HKRRL), Jin-Qi Gao and research student at BUCEA, for their active contribution to this research.

Chen, M. Z., Xiao, F. P., Putman, B., Leng, B. B., and Wu, S. P. (2014). Investigation on physical properties of waste cooking oil-rejuvenated bitumen binder. Constr. Build. Mater. 59, 10-16.

Corbett, L.. (1975). Reconstituted Asphalt Paving Compositions US Patent 3793189.

Dessouky, S., Reye, C., Llias, M., Contreras, D., and Papagiannakis, A. T. (2011). Effect of preheating duration and temperature conditioning on the rheological properties of bitumen. Constr. Build. Mater. 25, 2785-2792. doi: 10.1016/j. conbuildmat.2010.12.058

Dony, A., Colin, J., Bruneau, D., Drouadaine, I., and Navaro, J. (2013). Reclaimed asphalt concrete with high recycling rates: change in reclaimed binder 
properties according to rejuvenating agent. Constr. Build. Mater. 41, 175-181. doi: 10.1016/j.conbuildmat.2012.11.031

Garciaa, A., Schlangen, E., Ven, M., and Beltrana, G. S. (2010). Preparation of capsules containing rejuvenators for their use in asphalt concrete. J. Hazard. Mater. 184, 603-611. doi: 10.1016/j.jhazmat.2010.08.078

Holleran, G., Wieringga, T., and Tailby, J. (2006). Rejuvenation Treatments for Aged Pavements. Transport Research Board, ITRD E215026. Washington D.C: National Academies Press.

Huang, B., Li, G., Vukosavljevic, D., Shu, X., and Egan, B. K. (2005). Laboratory investigation of mixing hot mix asphalt with reclaimed asphalt pavement. Trans. Res. Record J. Trans. Res. Board 1921, 37-45.

Kallas, B. F. (1984). Flexible Pavement Mixture Design Using Reclaimed Asphalt Concrete. Report No. FHWA/RD-84/088, Final Report. College Park, Md: Asphalt Institute.

Leandri, P., Cuciniello, G., and Losa, M. (2012). Study of Sustainable high performance bituminous mixtures. Proc. Soc. Behav. Sci. 53, 495-503. doi: 10.1016/j.sbspro.2012.09.900

Lu, X., and Isacsson, U. (2009). Effect of aging on bitumen chemistry and theology. Constr. Build. Mater. 16, 15-22.

Lukens, L. A. (1998). Method for Recycling and Rejuvenating Asphalt Pavement US Patent 5766333.

McGovern, E. W. (1987). Pavement Dressing Conditioner Formed of Tar, an Aromatic Solvent and a Bituminous Pavement Rejuvenator US Patent 4661378.

Miliutenko, S., Bjorklund, A., and Carlsson, A. (2013). Opportunities for environmentally improved asphalt recycling: the example of Sweden. J. Cleaner Prod. 41, 175-181.

Navaro, J., Bruneau, D., Drouadaine, I., Pouteau, B., Clin, J., and Dony, A. (2012). Observation and evaluation of the degree of blending of reclaimed asphalt concretes using microscopy image analysis. Constr. Build. Mater. 37, 135-143. doi: 10.1016/j.conbuildmat.2012.07.048

Romera, R., Santamaria, A., Pena, J. J., Munoz, M. E., Barral, M., Garcia, E., et al. (2006). Rheological aspects of the rejuvenation of aged bitumen. Rheol. Acta 45, 474-478. doi: 10.1007/s00397-005-0078-7
Shen, J., Amirkhanian, S. N., and Tang, B. (2009). Effects of rejuvenator on performance based properties of rejuvenated asphalt binder and mixtures. Constr. Build. Mater. 23, 1028-1034.

Specht, L. P., Khatchatourian, O., Brito, L. A. T., and Ceratti, J. A. P. (2007). Modeling of asphalt rubber rotational viscosity by statistical analysis and neural networks. Mater. Res. 10, 69-74. doi: 10.1590/s1516-1439200700010 0015

Takamura, K. (2008). Method of Rejuvenating Road Surfaces with Polymer Modified Asphalt Emulsions US Patent 7357594.

West, R., and Willis, J. R. (2013). Improved Mix Design, Evaluation and Materials Management Practices for Hot Mix Asphalt with High Reclaimed Asphalt Pavement Content. NCHRP Report 752. Washington D.C: National Academies Press.

Widyatrnoko, I. (2003). Mechanistic empirical mixture design for hot mix asphalt pavement recycling. Constr. Build. Mater. 22, 77-87. doi: 10.1016/j. conbuildmat.2006.05.041

Xiao, F., Amirkhanian, S. N., and Wu, B. (2011). Fatigue and stiffness evaluation of reclaimed asphalt pavement in hot mix asphalt mixtures. J. Test. Eval. 39, $153-160$.

Zargar, M., Ahmadinai, E., Asli, H., and Karim, M. R. (2012). Investigation of the possibility of using waste cooking oil as a rejuvenating agent for aged bitumen. J. Hazard. Mater. 233-234, 254-258. doi: 10.1016/j.jhazmat.2012.06.021

Conflict of Interest: The authors declare that the research was conducted in the absence of any commercial or financial relationships that could be construed as a potential conflict of interest.

Copyright (C) 2021 Suo, Chen, Yan, Tan, Li and Zhang. This is an open-access article distributed under the terms of the Creative Commons Attribution License (CC BY). The use, distribution or reproduction in other forums is permitted, provided the original author(s) and the copyright owner(s) are credited and that the original publication in this journal is cited, in accordance with accepted academic practice. No use, distribution or reproduction is permitted which does not comply with these terms. 